\title{
Interleukin-7-enhanced cytotoxic T lymphocyte activity after viral infection in marrow transplanted mice
}

\author{
A Abdul-Hai ${ }^{1}$, A Ben-Yehuda ${ }^{2}$ L Weiss ${ }^{1}$, G Friedman ${ }^{2}$, Z Zakay-Rones ${ }^{3}$, S Slavin ${ }^{1}$ and R Or ${ }^{1}$ \\ ${ }^{1}$ Department of Bone Marrow Transplantation and Cancer Immunobiology Research Laboratory, Hadassah University Hospital, \\ Jerusalem; ${ }^{2}$ Department of Internal Medicine, Geriatric Unit, Hadassah University Hospital, Jerusalem; and ${ }^{3}$ Department of \\ Virology, Hebrew University-Hadassah Medical School, Jerusalem, Israel
}

\section{Summary:}

Lethally irradiated BALB/c mice were reconstituted by syngeneic bone marrow transplantation (BMT), and injected with recombinant interleukin 7 (rIL-7), recombinant interleukin 2 (rIL-2), or saline 10 days posttransplantation. Intranasal infection with A/PR8/34 influenza virus 2 weeks after BMT was associated with the highest survival rate in the rIL-7-treated group. The protective mechanism elicited by rIL-7, as manifested by very low virus titers in the lung, involves $T$ and $B$ cell functions. High hemagglutinin inhibition antibody levels were observed on days 7 and 12 post-challenge in the rIL-7 mice. Moreover, the anti-influenza cytotoxic T lymphocyte activity was induced primarily by rIL-7, leaving the effect of rIL-2 on the same level as that of the control. Thus, rIL-7 promotes both $\mathrm{T}$ cell-mediated function and $B$ cell production during the immunodeficient state after BMT. This cytokine may prove a potential immunotherapeutic modality in BMT recipients.

Keywords: bone marrow transplantation; interleukin 7; T lymphocytes

Autologous bone marrow transplantation (BMT) is being used with increasing frequency to permit administration of otherwise lethal doses of irradiation, chemical agents or various combinations of both, in an attempt to eradicate tumor cells in patients with malignancies.,2 Numerous studies have shown the addition of myeloid growth factors to the treatment regimen after autologous BMT to hasten the time to durable engraftment of hematopoietic cells. ${ }^{3}$ In contrast to the recovery of the myeloid cells, the reconstitution of lymphocyte function is delayed, making it the causative mechanism for the prolonged immune deficiency state post-BMT, both with regard to protection from infection and immune-mediated anti-tumor activity. ${ }^{4-6}$

The research addressing the mechanism(s) of immune deficiency and its correction spans a wide variety of immunomodulators, including interleukins (IL), without tangible success. Investigations in $\mathrm{BALB} / \mathrm{c}$ mice dealing with the

Correspondence: Dr R Or, Department of Bone Marrow Transplantation, Hadassah University Hospital, PO Box 12000, Jerusalem 91120, Israel Received 21 May 1996; accepted 24 November 1996 induction of IL-2 mRNA and IL-2 production after syngeneic BMT (sBMT) showed early restoration of this cytokine, implying a relative minor role of endogenous IL-2 in the pathogenesis of post-BMT immune deficient state. ${ }^{7}$

Interleukin 7 (IL-7), a $25 \mathrm{kDa}$ glycoprotein isolated from the murine bone marrow stromal cell line, has been described as a growth promoting, and possibly differentiating, factor of pre-B cells and immature thymocytes. ${ }^{8-10}$ Endogenous IL-7 has also been found to be involved in the development of cytotoxic T lymphocytes (CTL), as evidenced by complete blocking of its activity by anti IL-7 serum. ${ }^{11}$ The cytokine has further been shown to promote $\mathrm{V}(\mathrm{D}) \mathrm{J}$ gene rearrangement in the precursor T cells. ${ }^{12} \mathrm{In}$ an earlier investigation, we probed the ability of IL-7 to induce rearrangement of the $\mathrm{V} \beta 8 \mathrm{~T}$ cell receptor gene after sBMT in mice; ${ }^{13}$ it appeared that rIL-7 is directly involved in signal transduction of both V(D)J and RAG-1 gene expression. Bolotin et $a l^{14}$ very recently found, in line with our results, that administration of IL-7 after BMT enhanced thymopoiesis, even when donor bone marrow was depleted of mature T lymphocytes.

The present murine study investigates the effect of rIL7 -induced gene rearrangement on immune function in the context of viral infection after sBMT in mice. The experiments were drafted so as to follow the kinetics of the specific immune response against influenza virus at the level of antibody production, as well as to detect generation of cytotoxic $\mathrm{T}$ lymphocytes.

\section{Materials and methods}

All animal procedures utilized in this study were approved by the Institutional Committee for Animal Experimentation.

\section{Mice}

Female BALB/c mice, aged 10-16 weeks, were obtained from the Hebrew University-Hadassah Medical School mouse colony. The animals were fed a regular diet and acidified water without antibiotics, and were maintained under standard conditions with no isolation.

\section{Total body irradiation}

The mice were positioned in radiation chambers and exposed to a total lethal dose of $800 \mathrm{cGy}$ delivered from 
a linear accelerator (Varian clinac $6 \mathrm{X}$ ) at a dose rate of $170 \mathrm{cGy} / \mathrm{min}$, at a source-to-skin distance of $80 \mathrm{~cm}$.

\section{Bone marrow transplantation}

The donor mice were killed by cervical dislocation; the long bones (femora, tibiae and humeri) were removed and the marrow cavities were flushed with RPMI 1640 medium (Biolab, Jerusalem, Israel) using a 25-gauge needle. Cell suspensions were filtered through a fine nylon mesh and washed twice in RPMI medium. Aliquots $(0.3 \mathrm{ml}$ medium containing $10^{7}$ nucleated cells) were injected intravenously into the lateral tail vein of recipient mice $24 \mathrm{~h}$ postirradiation.

\section{Administration of rIL-2 and rIL-7 in vivo}

All mice were subjected to total body irradiation and subsequent sBMT, after which they were divided into three groups (15 animals/group). One group was injected intraperitoneally with $\mathrm{rIL}-7$ ( $100 \mathrm{ng} \times 2$ /day for 10 days $)$, the second group received intraperitoneal rIL-2 (1000 units $\times 2 /$ day for 10 days), and the third group was given saline (control). A fourth group of non-transplanted mice served as untreated (normal) animals. Each experiment was repeated three times. Human rIL-2 was kindly provided by Eurocetus/Chiron BV (Amsterdam, The Netherlands) as $1 \mathrm{mg}$ proleukin $\left(18 \times 10^{6}\right.$ international units is equivalent to $3 \times 10^{6}$ cetus units) and human rIL-7 was a gift from Peprotech (Princeton, NJ, USA) in the form of lyophilized powder soluble in water. The cytokine was reconstituted in phosphate buffered saline (PBS) to a concentration of $100 \mathrm{ng} / \mathrm{ml}$.

\section{Challenge with influenza virus}

Susceptibility of the sBMT recipients and non-transplanted (normal) mice to influenza virus infection was tested by intranasal administration of the live influenza A/PR/8/34 H1N1 virus 2 weeks after BMT. Each mouse received $50 \mu \mathrm{l}$ PBS containing $10^{6} 50 \% / \mathrm{EID}_{50}$ under light anesthesia. Survial was monitored daily during the experimental period.

\section{Cytotoxic T lymphocyte (CTL) cultures in vitro}

Single-cell preparations from pooled spleens from mice (three mice/group) immunized 2 weeks previously with the influenza virus or recombinant vaccinia virus were cultured. ${ }^{15}$ Briefly, $15 \times 10^{6}$ spleen cells were mixed with $5 \times 10^{6}$ syngeneic, irradiated (2000 rad) A/PR/8 influenza virus-infected feeder spleen cells in $10 \mathrm{ml}$ complete medium (RPMI 1640, 10\% FCS, $5 \times 10^{-5} \mathrm{~m}$ 2-mercaptoethanol, penicillin and streptomycin). The cultures were harvested after 7 days incubation at $37^{\circ} \mathrm{C}$ and assayed for ${ }^{51} \mathrm{Cr}$ release. The responding CTL were harvested and tested for their activity.

\section{${ }^{51} \mathrm{Cr}$ release cytotoxicity assay}

For this assay $\mathrm{P}_{815}$ cells were used as targets. The cells were washed twice with serum-free medium (RPMI 1640), infected with $50 \mu \mathrm{l}$ of $\mathrm{A} / \mathrm{PR} / 8$ influenza virus-infected allantoic fluid, and labeled with $150 \mu \mathrm{Ci}{ }^{51} \mathrm{Cr}$ (Amersham, Arlington Heights, IL, USA) for $90 \mathrm{~min}$ at $37^{\circ} \mathrm{C}$ as previously described. ${ }^{16}$ Four concentrations of CTL (effectorto-target ratios of $30: 1,10: 1,3: 1$ and $1: 1)$ were added in triplicate to $10^{4}$ influenza-infected target cells in 96-well U-shaped bottom plates in RPMI 1640 with $10 \%$ FCS. The plates were centrifuged and incubated for $6 \mathrm{~h}$ at $37^{\circ} \mathrm{C}$. An aliquot $(100 \mu \mathrm{l})$ of supernatant was then removed from each well, and ${ }^{51} \mathrm{Cr}$ release was determined in a gamma counter. Spontaneous and maximal release were determined by incubating ${ }^{51} \mathrm{Cr}$-labeled $\mathrm{A} / \mathrm{PR} / 8$ influenza virus infected $\mathrm{P}_{815}$ cells with either $100 \mu \mathrm{l}$ media or $100 \mu \mathrm{l}$ of Triton $\mathrm{X}$ 100 (Fisher Scientific, Pittsburgh, PA, USA). The percentage of specific chromium release was calculated by subtracting spontaneous released counts per minute from release in the presence of CTL divided by the maximal released counts per minute minus the spontaneous release. This fraction was multiplied by 100 .

\section{Serum hemagglutination inhibition antibody titration}

Individual blood samples were collected by bleeding from the retro-orbital sinuses and sera were treated with vibrio cholera receptor destroying enzyme (Sigma, St Louis, MO, USA) for $18 \mathrm{~h}$ at $37^{\circ} \mathrm{C}$, followed by heat inactivation for $30 \mathrm{~min}$ at $56^{\circ} \mathrm{C}$. HI antibody titers were determined by microtitration using four hemagglutination units.

\section{Protection}

The susceptibility of each experimental group to influenza infection was tested by an intranasal challenge with $50 \mu \mathrm{l}$ PBS containing the lethal dose of $10^{6} 50 \% / \mathrm{EID}_{50}$ units, administered under light anesthesia 2 weeks after immunization. Seven and 12 days following challenge, mice were killed and their lungs removed, frozen in PBS containing $0.1 \%$ gelatin and stored at $-70^{\circ} \mathrm{C}$. To detect viable virus in lungs, $2 \times 10^{4}$ MDCK cells were seeded into each well of a 96-well tissue culture microplate and incubated overnight at $37^{\circ} \mathrm{C} . \mathrm{A} / \mathrm{PR} / 8$ influenza virus-infected allantoic fluid and the lung sample suspensions were serially diluted in 10fold steps from $10^{-1}$ to $10^{-9}$ in DMEM containing $1 \%$ bovine serum albumin, $0.01 \%$ sodium bicarbonate, and $0.1 \%$ gentamicin. A 25- $\mu$ l aliquot of an appropriate dilution of each dilution was added to MDCK cells in triplicate wells of tissue culture plates. After $1 \mathrm{~h}$ incubation at $37^{\circ} \mathrm{C}, 175 \mu \mathrm{l}$ DMEM with bovine serum albumin, sodium bicarbonate, gentamicin and $2 \mu \mathrm{g} / \mathrm{ml}$ trypsin (Sigma type IX from porcine pancreas, crystallized, dialyzed, lyophilized) was added to each well. Forty-eight hours later, the virus titers were established by determining the hemagglutination titers of supernatants from each individual well. The TCID $_{50}$ was calculated using the Reed and Muench method ${ }^{17}$ and given in $\log _{10}$ units.

\section{Statistical evaluation}

The independent $t$ test was used for comparison between the groups. Differences at the $P<0.05$ level were considered significant. 


\section{Results}

Effect of rIL-2 and rIL-7 on influenza viral replication in the lung of post-sBMT mice

Lungs were harvested 7 and 12 days post-viral inoculation, homogenized, serially diluted and seeded on MDCK cells. The $\log _{10}$ tissue culture infectious dose of the influenza titers was used to express the rate of viral replication in the lungs in mice that underwent BMT and treated by either saline or each of the cytokines. As seen in Table 1, 7 days after inoculation, the rate of viral replication was highest among the controls, followed by IL-2-treated mice, the IL7 -treated group showing the lowest viral titers. Complete clearance of the influenza virus from the lungs of the IL7 treated mice was observed by day 12, while the control and IL-2 group still showed a heavy load of the virus (differences between IL-7 vs IL-2 and saline groups were statistically significant, $P<0.05$ for both days tested). In parallel, survival was monitored within each of the experimental group. Within 2 weeks of influenza challenge, $>90 \%$ of the rIL2 and saline-treated mice succumbed; in the rIL-7 group $>40 \%$ survived for more than 20 days $(P=0.0035)$ (data not shown). The dosages of the two cytokines used in this study did not lead to toxic death in the virus-free controls.

\section{Effect of rIL-2 and rIL-7 on hemagglutination inhibition antibody titers post-sBMT}

To elucidate the mechanism(s) underlying the high viral clearance in the IL-7-treated mice, HI antibody serum titers were measured 7 and 12 days post-inoculation. While all three groups demonstrated HI titers considered protective against influenza infection (1:40), ${ }^{15}$ the rIL-7-treated mice had the highest titer on day 7 , increasing to significantly high values on day $12(P<0.05$; Figure $1 \mathrm{a})$.

\section{Effect of rIL-2 and rIL-7 on CTL activity level post- $s B M T$}

To assay specific cytotoxicity against the influenza virus, CTL activity was measured in splenic cells 12 days after viral inoculation. The IL-7-treated mice showed the highest

Table 1 Pulmonary infection of mice challenged with live A/PR/8 influenza virus after sBMT and subsequent IL-2 and IL-7 treatment

\begin{tabular}{|c|c|c|c|c|c|c|c|}
\hline Treatment group & $\log _{10}$ & $\mathrm{TCID}_{5}$ & ${ }_{50}$ of $l u$ & ing infl & luenza & titers & Mean \pm s.d. \\
\hline \multicolumn{8}{|l|}{ Day 7} \\
\hline Normal & 3.5 & 4.25 & 3.8 & & & & $3.850 \pm 0.377$ \\
\hline Control (saline) & 5.8 & 4.25 & 4.8 & 6.25 & 4.8 & & $5.180 \pm 0.819$ \\
\hline rIL-2 & 4.25 & 4.25 & 4.5 & 4.5 & 4.25 & 3.8 & $4.258 \pm 0.250$ \\
\hline rIL-7 & 2.8 & 3.5 & 3.5 & 3.25 & 2.8 & & $3.170 \pm 0.353$ \\
\hline \multicolumn{8}{|l|}{ Day 12} \\
\hline Normal & $<1$ & 1.8 & 1.8 & & & & $1.533 \pm 0.462$ \\
\hline Control (saline) & 2.5 & 2.5 & 2.5 & $<1$ & & & $2.125 \pm 0.750$ \\
\hline rIL-2 & 3.5 & 3.25 & 3.25 & 2.5 & & & $3.125 \pm 0.433$ \\
\hline rIL-7 & $<1$ & $<1$ & $<1$ & $<1$ & & & $<1$ \\
\hline
\end{tabular}

The values refer to individual mice.

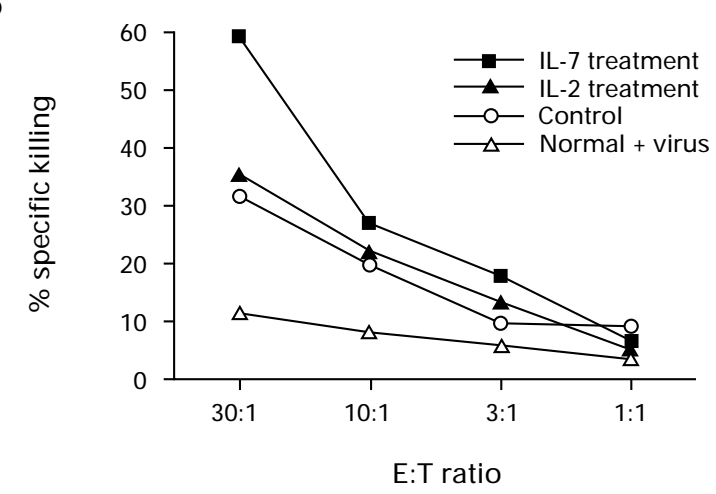

Figure 1 (a) Effect of IL-2 and IL-7 treatment on antibody formation following sBMT and intranasal challenge with live A/PR/8 influenza virus. Values represent mean \pm s.d. of three experiments. (b) Activity of antiinfluenza cytotoxic $\mathrm{T}$ lymphocytes in mice inoculated with the virus. Percentage of ${ }^{51} \mathrm{Cr}$ released from influenza-infected $\mathrm{P}_{815}$ cells by spleen cells from mice inoculated 2 weeks after marrow transplantation. CTL-to-target $(\mathrm{E}: \mathrm{T})$ ratios of $30: 1,10: 1,3: 1$ and $1: 1$ percentage release was calculated by subtracting spontaneous released counts per minute from release in presence of CTL divided by maximal released counts per minute minus spontaneous release. Values represent 1/3 representative experiments.

CTL activity against the influenza virus, especially at an effector-to-target ratio of 30:1 (Figure 1b). The transplanted saline group (control) showed enhanced cytotoxic activity superseding that of the non-transplanted-virus challenged (normal) mice (Figure 1b). This phenomenon was also reflected in the level of viral infection in the lungs (Table 1). This effect is probably due to the known 'upshoot' of cytotoxicity occurring after TBI. The CTL activity in the IL-2-treated group was similar to that seen in the controls (saline).

\section{Discussion}

Recipients of marrow-ablative chemotherapy or chemoradiotherapy prior to BMT are at high risk of viral infection until engraftment of lymphoid precursors evolve into mature $\mathrm{T}$ and $\mathrm{B}$ cells capable of restoring normal protective mechanisms. ${ }^{4,6,18}$ The precise cellular and molecular in vivo events that underlie the immunosuppressive state post-BMT are largely obscure. In the present murine study, IL-7 treatment post-sBMT induced a specific immune 
response, providing protection from influenza virus infection by increasing both antibody production and cytotoxic cellular activity.

IL-7 is a potent stimulus in generating proliferative signals to $\mathrm{B}$ and $\mathrm{T}$ cell precursors and, to a lesser extent, in activating mature T cells. ${ }^{19-21}$ In fact, IL-7-deficient mice have demonstrated profound inhibition of lymphoid development, in contrast to gene inactivation of other cytokines. $^{22}$ It has been suggested that the lymphokine acts via mechanism(s) enabling it to support the rearrangement of the $\mathrm{T}$ cell receptor $\beta$ gene in cultured thymocytes. ${ }^{12}$ In a previous study rIL-7 immunotherapy was shown to induce early transcription of the RAG-1 gene, and consequent accelerated $\mathrm{V} \beta 8$ gene rearrangement. ${ }^{13}$ In the present investigation, we used an in vivo approach to pinpoint the fundamental role of $\mathrm{T}$ cell receptor gene rearrangement within the realm of IL-7 activity inducing protection from viral infection after BMT. The cytokine boosted survival after challenge with influenza virus post-sBMT.

With regard to IL-2, there is accumulating data that immunotherapy with this cytokine may decrease the danger of relapse of hematologic malignancies. ${ }^{23,24}$ It has been postulated that IL-2 might induce, or augment, the graftversus-leukemia (GVL) reaction via its effect on $\mathrm{T}$ and nonT lymphocytes. ${ }^{25,26}$ In animals, IL-2 has been shown to induce a GVL effect; however, it may also either exacerbate or protect against graft-versus-host disease (GVHD) depending on the model, the IL-2 regimen and time of administration. ${ }^{27-29}$ In the post-transplant set up, IL-2 is a potential immunomodulator affecting primarily mature $\mathrm{T}$ cells, inducing an anti-tumor effect.

There exists compelling evidence ${ }^{12-14}$ that IL-7 stimulates immature $\mathrm{T}$ and $\mathrm{B}$ cells, which turns it into a promising agent in the fight against complications occurring after BMT or in other immunodeficiency states, because (1) it enhances the development of the $\mathrm{V}(\mathrm{D}) \mathrm{J}$ reconstitutional apparatus and promotes immune recovery; (2) it likely generates anti-tumor effects by pathways different from those of IL-2; and (3) it appears to be relatively nontoxic in animals. ${ }^{12,19,30}$

Using sBMT as a basic model, it appeared that IL-7 is capable of rendering protection from viral infection, as opposed to the lesser efficacy of IL-2. The mechanism underlying the reduced viral replication, to nearly zero on day 12 post-infection, in the IL-7-treated animals can be attributed in part to the correlation found to exist between the kinetics of the serum HI antibodies, CTL activity and viral clearance from the lungs. IL-2 was capable of inducing a certain level of, presumably CD4 cell-mediated, protection against influenza virus infection. The phenomenon of the relatively low CTL activity mounted by the normal mice has been reported before. ${ }^{15}$ The augmentation of the CTL response following cytokine therapy might be a result of stimulation-susceptible lymphocytes post-BMT.

In the light of these findings it is justifiable to assume that IL-7 activity was targeted at more than one cell type, that is induction of specific anti-influenza $\mathrm{T}$ and $\mathrm{B}$ cell response. Within the network of cytokine regulation, nonspecific immune response, such as natural killer (NK) and lymphokine-activated killer cells, remains a possibility. We postulate that the prompt response to IL-7 administration reflects a lack of IL-7 production after BMT, a factor that can only be established once accurate appropriate assays become available.

In a mouse model of fibrosarcoma, IL-7 surpassed IL-2 and IL-4 in generating CTL activity against the tumor, ${ }^{31,32}$ findings that inspired us to examine specific cell cytotoxicity against viral infection. The CTL activity against the influenza virus was primarily IL-7-induced, leaving the effect of IL-2 on the same plane as that of the saline in the controls. Considering that, unlike IL-2, IL-7 is a growth factor for the earliest lymphoid cells, ${ }^{22}$ its mechanism of action in the protection from viral infection might be primarily CD8-mediated. It should be taken into account, however, that in the murine complex each of the cytokines may elicit CTL activity from different cell populations. ${ }^{19}$

As far as we could ascertain, the present study is the first to show that in vivo administered rIL-7 boosts specific $\mathrm{T}$ cell differentiation and improves $\mathrm{B}$ cell function postsBMT. Although clinical trials with rIL-7 in BMT patients are still awaited, and its effects on the basic malignant disease, ${ }^{33} \mathrm{GVHD}$, rejection and, especially, induction of GVL via non-specific NK cells remain to be established, the current data suggest a potential role of this cytokine as an immunotherapeutic modality early after BMT.

\section{Acknowledgements}

This work was supported in part by the Robert A Rosenblum Research Fund, and in part by a grant from HJ Leir to G.F.

\section{References}

1 Armitage JO. Bone marrow transplantation. New Engl J Med 1994; 330: 827-838.

2 Canellos GP, Nadler L, Takvorian T. Autologous bone marrow transplantation in the treatment of malignant lymphoma and Hodgkin's disease. Semin Hematol 1988; 25 (Suppl. 2): $58-65$.

3 Bishop MR, Anderson JR, Jackson JD et al. High-dose therapy and peripheral blood progenitor cell transplantation: effects of recombinant human granulocyte-macrophage colony-stimulating factor on the autograft. Blood 1994; 83: 610-616.

4 Petersen FB, Buckner CD, Clift RA et al. Infectious complications in patients undergoing marrow transplantation: a prospective randomized study of the additional effect of decontamination and laminar air flow isolation among patients receiving prophylactic systemic antibiotics. Scan J Infect Dis 1987; 19: 559-567.

5 Horowitz MM, Gale RP, Sondel PM et al. Graft-versusleukemia reactions after bone marrow transplantation. Blood 1990; 75: 555-562.

6 Wingard JR, Chen DY, Burns WH et al. Cytomegalovirus infection after autologous bone marrow transplantation with comparison to infection after allogeneic bone marrow transplantation. Blood 1988; 71: 1432-1437.

7 Abdul-Hai A, Lorberboum-Gliski H, Mechushtan A et al. Involvement of interleukin-2 in immunologic reconstitution following bone marrow transplantation in mice. J Interf Cytokine Res 1995; 15: 95-101.

8 Namen AE, Lupton S, Hjerrild K et al. Stimulation of B-cell 
progenitors by cloned murine interleukin-7. Nature 1988; 333: 571-573.

9 Goodwin RG, Lupton S, Schmierer A et al. Human interleukin 7: molecular cloning and growth factor activity on human and murine B-lineage cells. Proc Natl Acad Sci USA 1989; 86: 302-306.

10 Sakata T, Iwagami S, Tsuruta Y et al. Constitutive expression of interleukin-7 mRNA and production of IL-7 by a cloned murine thymic stromal cell line. J Leukocyte Biol 1990; 48: 205-212.

11 Alderson MR, Sassenfeld HM, Widmer MB. Interleukin-7 enhances cytolytic $\mathrm{T}$ lymphocyte generation and induces lymphokine-activated killer cells from human peripheral blood. J Exp Med 1990; 172: 577-587.

12 Muegge K, Vila MP, Durum SK. Interleukin-7: a cofactor for $\mathrm{V}(\mathrm{D}) \mathrm{J}$ rearrangement of the T cell receptor $\beta$ gene. Science 1993; 261: 93-95.

13 Abdul-Hai A, Or R, Slavin S et al. Stimulation of immune reconstitution by interleukin-7 after syngeneic bone marrow transplantation in mice. Exp Hematol 1996; 24: 1416-1422.

14 Bolotin E, Smogorzewska M, Smith S et al. Enhancement of thymopoiesis after bone marrow transplant by in vivo interleukin-7. Blood 1996; 88: 1887-1894.

15 Ben-Yehuda R, Ehleiter D, Hu AR, Weksler ME. Recombinant vaccinia virus expressing the PR/8 influenza hemagglutinin gene overcomes the impaired immune response and increased susceptibility of old mice to influenza infection. $J$ Infect Dis 1993; 168: 352-357.

16 Danenberg HD, Ben-Yehuda A, Zakay-Rones Z, Friedman G. Dehydroepiandrosterone (DHEA) treatment reverses the impaired immune response of old mice to influenza vaccination and protects from influenza. Vaccine 1995; 13: 1-4.

17 Reed LJ, Muench M. A simple method of estimating fifty percent endpoints. Am J Hyg 1938; 27: 493-497.

18 Lum LG. The kinetics of immune reconstitution after human marrow transplantation. Blood 1987; 69: 369-380.

19 Lynch DH, Miller RE. Induction of murine lymphokineactivated killer cells by recombinant IL-7. J Immunol 1990; 145: 1983-1990.

20 Touw I, Pouwels K, van Agthoven T et al. Interleukin-7 is a growth factor of precursor $\mathrm{B}$ and $\mathrm{T}$ acute lymphoblastic leukemia. Blood 1990; 75: 2097-2101.

21 Alderson MR, Tough TW, Ziegler SF, Grabstein KH. Interleukin 7 induces cytokine secretion and tumoricidal activity by human peripheral blood monocytes. J Exp Med 1991; 173: 923-930.

22 von Freeden-Jeffry U, Vieira P, Lucian LA et al. Lymphopenia in interleukin (IL)-7 gene-deleted mice indentifies IL-7 as a nonredundant cytokine. J Exp Med 1995; 181: 15191526.
23 Massumoto C, Benyunes MC, Sale G et al. Close simulation of acute graft-versus-host disease by interleukin-2 administered after autologous bone marrow transplantation for hematologic malignancy. Bone Marrow Transplant 1996; 17: 351-356.

24 Messina C, Zambello R, Rossetti F et al. Interleukin-2 before and/or after autologous bone marrow transplantation for pediatric acute leukemia patients. Bone Marrow Transplant 1996; 17: 729-735.

25 Valteau-Couanet D, Rubie H, Meresse Y et al. Phase I-II study of interleukin-2 after high-dose chemotherapy and autologous bone marrow transplantation in poorly responding neuroblastoma. Bone Marrow Transplant 1995; 16: 515-520.

26 Robinson N, Sanders JE, Benyunes MC et al. Phase I trial of interleukin-2 after unmodified HLA-matched sibling bone marrow transplantation for children with acute leukemia. Blood 1996; 87: 1249-1254.

27 Sykes M, Romick ML, Sachs DH. Interleukin 2 prevents graftversus-host disease while preserving the graft-versus-leukemia effect of allogeneic T cells. Proc Natl Acad Sci USA 1990; 87: 5633-5637.

28 Sykes M, Harty MW, Szot GL, Pearson DA. Interleukin-2 inhibits graft-versus-host disease-promoting activity of $\mathrm{CD}^{+}$ cells while preserving CD4- and CD8-mediated graft-versusleukemia effects. Blood 1994; 83: 2560-2569.

29 Weiss L, Reich S, Slavin S. Use of recombinant human interleukin-2 in conjunction with bone marrow transplantation as a model for control of minimal residual disease in malignant hematological disorders. I. Treatment of murine leukemia in conjunction with allogeneic bone marrow transplantation and IL-2-activated cell-mediated immunotherapy. Cancer Invest 1992; 10: 19-26.

30 Pavletic Z, Benyunes MC, Thompson JA et al. Induction by interleukin-7 of lymphokine-activated killer activity in lymphocytes from autologous and syngeneic marrow transplant recipients before and after systemic interleukin-2 therapy. Exp Hematol 1993; 21: 1371-1378.

31 Jicha D, Mule J, Rosenberg S. Interleukin 7 generates antitumor cytotoxic $\mathrm{T}$ lymphocytes against murine sarcoma with efficacy in cellular adoptive immunotherapy. J Exp Med 1991; 174: $1511-1515$.

32 Lynch D, Namen A, Miller R. In vivo evaluation of the effects of IL-2, IL-4 and IL-7 on enhancing the immunotherapeutic efficacy of anti-tumor CTL. Eur J Immunol 1991; 21: 29772980.

33 Touw I, Pouwels K, van Agthoven T et al. Interleukin-7 is a growth factor of precursor B and $\mathrm{T}$ acute lymphoblastic leukemia. Blood 1990; 75: 2097-2101. 